\title{
Мотивационные факторы \\ телевизионного потребления российских детей и подростков
}

(на примере Москвы, Нижнего Новгорода, Ростова-на-Дону)

Гелия Филаткина

Майя Давлетшина

В статье рассматриваются особенности телевизионного потребления молодым поколением России на примере жителей трех городов - Москвы, Нижнего Новгорода и Ростова-на-Дону. Авторы, используя метод глубинных интервью, проведенных с 24 респондентами, пришли к выводу, что несмотря на активное использование цифровых технологий российская молодежь все еще смотрит телевизор, чтобы удовлетворить свои потребности в информации, развлечении, социализации, образовании 1 .

Ключевые слова: молодежь, телевидение, медиапотребление, Россия, мотивация. (c) Филаткина Гелия Сергеевна кандидат филологических наук, старший преподаватель кафедры зарубежной журналистики и литературы факультета журналистики МГУ имени М.В. Ломоносова (г. Москва, Россия), geliafilatkina@gmail.com

() Давлетшина Майя Ильдаровна аспирантка кафедры теории и экономики СМИ факультета журналистики МГУ имени М.В. Ломоносова (г. Москва, Россия), majsondavl@gmail.com

\section{Актуальность исследования}

Изучение особенностей медиапотребления детей и подростков представляется особенно актуальным в свете растущей цифровой трансформации медиасреды. Цифровизация оказывает большое влияние на молодую аудиторию, формируя ее медиапотребление, которое отличается высокой степенью вовлеченности в процесс создания и распространения медиа, активностью и самостоятельностью при выборе контента, нелинейностью, мобильностью.

Аудитория детей и подростков в возрасте от 10 до 19 лет, численность которых в современной России составляет порядка 15 млн человек², представляется наименее изученной с точки зрения потребления медиа, поскольку, согласно условным хронологическим рамкам молодые люди еще не достигли совершеннолетнего возраста и не попадают в полном объеме в выборку медиаизмерителей. Однако представители именно этой возрастной группы родились и взрослели в условиях цифровизации, в отличие от других поколений, вынужденных приобщаться к ней в более зрелом возрасте.

Несмотря на процессы цифровизации, развитие Интернета, использование мобильных устройств, традиционные медиа, в частности телевидение, остаются все еще 
востребованными среди молодой аудитории. И хотя современные социологические исследования фиксируют ежегодное сни жение потребления телевидения российской молодежью, которое достигает 7-8\%3, оно все еще продолжает сохранять довольно высокие показатели. Согласно данным Mediascope и TVIndex (TAM), лидером по продолжительности смотрения телевизионных каналов становится младшая возрастная группа: дети 4-10 лет смотрят телевизор до 125 мин в день. Подростки 11-15 лет и учащиеся старших классов (16-18 лет) потребляют телевидение меньше - в пределах часа в сутки. Наиболее востребованным телевизионным контентом для детей и подростков оказываются сериалы (24\%), фильмы (16\%) и мультсериалы (16\%)․․

\section{Теоретические рамки исследования}

Одним из важных теоретических направлений, использованных в исследовании, является поколенческая теория Н. Хоува и У. Штрауса (2007), согласно которой существует следующая классификация поколений: поколение X(1961-1982), поколение $Y$ (1982-2004) и поколение Z (2005 - наст. время). В данном исследовании акцент делается именно на изучении медиапотребления поколения Z, или так называемого «цифрового поколения». Их взросление проходит в полном взаимодействии с новыми технологиями, которые уже являются неотьемлемой частью их жизни.

Медиапотребление молодежи вызывает большой интерес у исследователей, разрабатывающих различные теории и концепции, выявляющие мотивационные факторы потребления массмедиа молодыми людьми. Согласно теории использования и удовлетворения (Uses \& Gratifications Theory), предложенной Дж. Блумлером и Э. Катцем (1974), аудитория выбирает те или иные медиа для того, чтобы удовлетворить свои потребности: потребности в информации, образовании, самоидентификации, раз- влечении, социализации (McQuail, Blumler, Brown, 1972). К этому перечню могут быть добавлены социальные и коммуникационные потребности, приобщение к какому-либо коллективу, группе, субкультуре, а также обращение к медиа в силу привычки (Greenberg, 1974).

Исследователи также изучают, как обращение людей к медиа помогает создать баланс негативных и позитивных эмоций (Zillmann, Bryant, 1985). Анализируется феномен активного потребления медиаконтента на стриминговых сервисах, который в первую очередь характеризуется желанием удовлетворить потребность в получении удовольствия, а также потребность в поиске сенсационного (Shim, Kim, 2018).

Исходя из потребности молодой аудитории в телевидении, рассматривается эффективность образовательного телевизионного контента (Mares, Sivakumar, Stephenson, 2015), влияние фонового медиапотребления на детей и подростков (Masur, Flynn, Olson, 2015; Pempek, Kirkorian, Anderson, 2014), воздействие агрессивного телевизионного контента на поведение молодого поколения (Bhatti, Hassan, 2014; Khurana, Bleakley, Ellithorpe et al., 2019). Также изучается роль телевидения в социализации детей и их умении выражать собственные эмоции (Scherr, Mares, Bartsch, Götz, 2017).

В российском научном дискурсе особое внимание уделяется различию мотивов телепросмотра среди младших и старших поколений (Полуэхтова, 2018); запросах к телевизионному медиаконтенту жителей центральных и отдаленных регионов Российской Федерации (Аникина, 2017; Образцова, 2014). Изучается детское телевидение и его роль в формировании речевой культуры молодого поколения (Лащук, Толоконникова, Хорошилова, 2018). Исследователи также делают акцент на особенностях медиапотребления в цифровой 
среде (Вартанова, 2011; Полуэхтова, 2016; Кульчицкая, Вартанов, Дунас, Салихова и др. 2019 (б)) и рассматривают наиболее эффективные методы изучения медийного потребления молодежи (Кульчицкая, Вартанов, Дунас, Салихова и др. 2019 (а); Образцова, Фролова, 2017).

\section{Методологическая база}

Мы провели исследование медиапотребления «цифровой молодежи» России и попытались выявить мотивационные факторы, которые подталкивают молодую аудиторию к обращению к телевизионному контенту. Для этого были проведены 24 глубинных интервью с представителями молодежной аудитории в Москве, Нижнем Новгороде и Ростове-на-Дону. Эти российские города насчитывают свыше миллиона жителей, обладают развитой инфраструктурой и крупными университетами. Москва представляет медиапривычки «цифровой молодежи» столичного мегаполиса, Нижний Новгород является центром Поволжья, Ростов-на-Дону - крупнейший город юга России.

В качестве респондентов выступили дети и подростки в возрасте от 10 до 19 лет. Данный возрастной диапазон был выбран в связи с тем, что, согласно наиболее распространенной в России периодизации детства Д. Эльконина (1989), можно полностью охватить период подросткового развития, а также раннее юношество. Это делает более простой задачу сопоставления мотивов обращения детей и подростков к медиа, и в частности к телевидению, с их базовыми психологическими потребностями, такими как стремление к новым знаниям и информации, потребность в общении и группировании со сверстниками, желание "примерить» на себя различные социальные роли, необходимость сформировать «я-концепцию» и др.

Респонденты были разделены на три возрастные группы: учащиеся младшей
(10-12 лет) и средней школы (13-15 лет) и школьники старших классов и первых курсов вузов (16-19 лет), по восемь респондентов от каждого города.

Участникам интервью задавались вопросы исходя из специфики их медийного потребления и мотивации обращения к той или иной медийной платформе. Вопросы были разделены на четыре основных блока. В первом блоке требовалось выяснить предпочтения респондентов в формах медиапотребления с точки зрения выбора конкретного медиаресурса - печатная пресса, Интернет, радио, телевидение, смартфон, книга. Второй блок вопросов был призван определить приоритеты в выборе медиконтента: было важно выявить тип контента, потребляемого с мобильных устройств, из мобильных приложений, из Интернета, социальных сетей, а также из традиционных медиа - печатной прессы, радио и телевидения. Третий блок вопросов выявлял отношение респондентов к различным медиаресурсам: дети и подростки объясняли, какие ресурсы им больше всего нравятся или не нравятся, видят ли они перспективы развития того или иного медиа, какую пользу или вред они могут принести. Также было важно понять, какие группы потребностей удовлетворяются при обращении молодых людей к определенным медиаресурсам или контенту - информационные (потребность в новой актуальной информации), образовательные (потребность в получении новых знаний), развлекательные (потребность в получении развлечения), социальные (потребность в объединении в группы по интересам), инструментальные (потребность в покупке или заказе услуг, вещей), коммуникационные (потребность в общении). Ответы респондентов были проанализированы методом дискурс-анализа, что позволило выявить специфику медиапотребления и мотивацию детей и подростков при обращении к телевидению. 


\section{Результаты эмпирического исследования}

В ходе анализа глубинных интервью было выявлено, что юная аудитория (10-12 лет), несмотря на обладание современными мобильными устройствами, все же потребляет телевидение. Дети включают телевизор для того, чтобы удовлетворить свои потребности:

- в информации: «Ну, потому что, там иногда узнаю новости, что-то из мира, потому что я часто не путешествую, еще там показывают погоду, я интересуюсь, чтобы пойти погулять на следующий день» (Анна, 11 лет, Нижний Новгород);

- в развлечении: «Иногда чтобы развлечься просто, когда скучно, или что-нибудь узнать» (Кирилл, 10 лет, Нижний Новгород);

- в социализации - для того, чтобы не испытывать чувство одиночества в пустом доме: «Чтобы одиноко не было, мне кажется, это происходило в те моменты, когда я оставался один, и чтобы был дополнительный шум, как будто бы жизнь кипит, я включал телевизор» (Давид, 12 лет, Москва);

- в образовании: «Я включаю какуюнибудь передачу о животных. Еще у меня есть любимая передача про разные фабрики...» (Марго, 12 лет, Москва).

В ходе интервью также было выявлено, что дети, проживающие в наиболее технологически развитом городе России Москве, смотрят телевизор меньше, чем дети, проживающие в Нижнем Новгороде и Ростове-на-Дону. Интервьюируемые также отметили, что, если и смотрят телевизор, то в основном детские и развлекательные каналы - «Карусель», «Дисней», СТ, «Пятница». При этом они также смотрят новостные программы на «Первом канале» и «России 1», хотя и не могут вспомнить названия новостных программ. Таким образом, источник информации становится для младшей возрастной группы респондентов второстепенным. Дети также не обсуждают увиденное по телевизору со своими друзьями и одноклассниками. Чаще всего в коллективах обсуждаются либо компьютерные игры, либо новости, увиденные в социальных сетях и Интернете.

Важно также отметить, что если дети, проживающие в Москве, называли в основном передачи неэфирных телевещателей, то респонденты из Нижнего Новгорода эфирные телеканалы. Москвичи используют телевизор чаще всего в качестве новостного и образовательного медиа в то время, как нижегородцы и ростовчане потребляют и развлекательный контент (мультфильмы, фильмы, развлекательные передачи). Характерным признаком также является совместное медиапотребление дети нередко смотрят телевизор с родителями и ближайшими родственниками.

Можно отметить также, что у детей 10-12 лет доминировал как фоновый просмотр, так и осознанный, т.е. целенаправленный выбор программ и телеканалов. Результаты интервью также показали, что для детей в целом характерно пассивное телесмотрение.

Аудитория школьников средних классов (13-15 лет) демонстрирует более широкий спектр мотивационных факторов. И прежде всего реализует свои развлекательные потребности - смотрит развлекательные программы, фильмы и сериалы, передачи о путешествиях:

«Не каждый, это по настроению. Когда скучно, когда весело или просто заняться нечем <...> Днем прихожу домой, поем, смотрю телевизор, потом опять иду гулять. То есть три раза ежедневно» (Руслан, 14 лет, Нижний Новгород);

«Какие-нибудь фильмы, которые в 9 часов на СТС идут, если мне интересно, я могу включить, посмотреть. Там вечером показывают фильмы, которые интересно мне посмотреть, а с телефона неудобно» (Настя, 15 лет, Нижний Новгород).

Реже проявляются образовательные и информационные потребности подрост- 
ковой аудитории - в просмотре познавательных программ и новостей:

«Ну да, если я ищу, не могу найти для себя что-то подходящее, я включаю новости, если они идут» (Никита, 13 лет, Ростов-на-Дону).

При этом подростки 13-15 лет, как и респонденты первой группы - школьники 10-12 лет - не фокусируют свое внимание на медиаресурсе, на котором они смотрят соответствующий контент. Для них источник (телеканал, передача) также играет второстепенную роль, как и для младшей группы респондентов. Вместе с тем подростки выражают стремление искать и смотреть понравившийся телеконтент на других платформах - например, в Интернете. Таким образом, они становятся младшей аудиторией, практикующей нелинейное телепотребление. Кроме того, данная возрастная группа практикует фоновое потребление телевидения, которое помогает подросткам создать определенный эмоциональный фон, избавиться от чувства одиночества или страха в пустом доме. В последнем случае можно говорить о соседстве развлекательных и социальных потребностей. Во многом фоновому просмотру способствует современная ситуация, которая складывается на телевизионном рынке России: появляются новые нишевые телеканалы, многие из которых работают по принципу фонового потребления, транслируя, например, ежедневно разные выпуски одной и той же передачи или сериала, что позволяет зрителю не вовлекаться во внимательный просмотр:

«Ну, включает его мой папа и смотрит телевизор, а дома я просто могу на фон включить телевизор, но не смотреть его. Да. Чтобы не было скучно и чтобы как-то нестрашно было» (Александра, 15 лет, Ростов-на-Дону).

Стоит также отметить различия в географии: респонденты из Москвы выразили минимальный интерес и потребность в те- левизионном просмотре, в отличие от интервьюируемых из региональных городов:

«Я не включаю телевизор, больше предпочитая Интернет» (Кристина, 15 лет, Москва).

Старшие школьники и студенты первых курсов вузов (16-19 лет) высказали практически минимальную потребность в потреблении телевидения, которое они замещают Интернетом. Сам телевизор они нередко используют в качестве монитора для просмотра видео и фото:

«Когда мы были школьниками, мы все приходили после школы и смотрели часто телевизор. А сейчас мы выросли и уже его не смотрим» (Григорий, 18 лет, Москва);

«Даже фоном стараюсь не то что не смотреть, но просто там ничего интересного нет. <...> Но сейчас в нем потребность отпала, потому что есть тот же Интернет, в котором можно найти очень много всего и то, что тебе интересно» (Никита, 16 лет, Москва);

«Телевизоры, но мы ими пользуемся исключительно подключая к телевизору телефон или ноутбук и выводя на экран какие-то фильмы или фото» (Настасья, 17 лет, Москва).

География проживания респондентов третьей группы так же, как и в двух предыдущих, оказывает влияние на просмотр телеконтента: в Москве молодые люди 16-18 лет практически не потребляют телевидение (это также можно наблюдать на приведенных выше примерах), тогда как в Нижнем Новгороде и Ростове-на-Дону молодежь смотрит общероссийские развлекательные телеканалы, фильмы, реже новости и историко-культурные передачи:

«Когда нечем заняться. Наверное, “Первый”, очень редко "Россия 1" и все. Какаянибудь развлекательная, что-то типа “Пятница". Всегда смотрю “Голос" в основном» (Екатерина, 17 лет, Нижний Новгород);

"“Культура". Мне интересна эта программа, о чем там разговаривают, и во- 
обще интересно. Есть очень интересные программы, которые помогают тебе разви ваться» (Наталья, 17 лет, Ростов-на-Дону).

И хотя свободного времени у представителей данной возрастной группы существенно меньше, чем у младшей аудитории, телевизор продолжает выполнять для них рекреационную функцию (просмотр развлекательных передач и только потом информационную (просмотр российских и зарубежных новостей) и гораздо реже познавательную (просмотр передач об истории и культуре).

\section{Выводы}

В результате анализа глубинных интервью мы обнаружили, что «цифровое поколение» России, родившееся в эпоху активного развития цифровых технологий, тем не менее не отказывается от потребления традиционных медиа, в частности телевидения, и активно практикует различные формы потребления телевизионного контента, такие, например, как линейный и нелинейный просмотр, фоновое, мультиэкранное потребление ит.д. В зависимости от возраста они это делают либо самостоятельно, либо совместно с родителями и другими членами семьи. Было выявлено, что кроме мотивации к развлечению, заполнению свободного времени, получению новых впечатлений и эмоций молодежь обращается к телевидению для удовлетворения образовательных (потребность в новых знаниях, навыках, умений), информационных (потребность в получении новостей) и социальных (потребность В компании, желание избежать чувство одиночества) потребностей.

Говоря о последних, стоит упомянуть фоновый просмотр, благодаря которому дети и подростки не испытывают чувства одиночества или страха в пустом доме. Несмотря на то что использование цифровых технологий молодежью является частью ее повседневной жизни, именно телевидение способно удовлетворить эту потребность.

Что касается развлекательного контента, все три группы респондентов предпочитают мультфильмы, фильмы, развлекательные передачи, сериалы. В целом характер телевизионного потребления молодых людей отличается пассивностью. Стоит также отметить, что дети (10-12 лет) и подростки (13-15 лет) нередко затруднялись назвать конкретный источник, в котором они получали ту или иную информацию. Таким образом, сам телевизионный источник для них становится второстепенным по сравнению с контентом. Школьники старших классов и студенты с такой проблемой не сталкивались.

Результаты интервью показали, что респонденты из Москвы уделяют телепросмотру минимальное количество времени, тогда как молодые люди из Нижнего Новгорода и Ростова-на-Дону довольно активно потребляют развлекательный и образовательный контент. Это демонстрирует географическое отличие потребностей молодежи в телевидении: Москва, являясь столицей России и одним из крупнейших мегаполисов в мире, способна предложить молодежи множество вариантов альтернативных видов деятельности для заполнения свободного времени.

Младшая группа респондентов в основном практикует совместный с родителями и взрослыми просмотр телепередач, тогда как подростки 13-15 лет потребляют телеконтент самостоятельно. Кроме того, подростки практикуют нелинейное телесмотрение: они выражают потребность в поиске и просмотре понравившегося телеконтента на других платформах - например, в Интернете. Старшеклассники и студенты в целом высказались за отказ от телевидения как ненужного и неинтересного для них источника информации в пользу Интернета, оставив тем не менее телевидению функцию развлечения. 
Каждая возрастная группа современных детей и подростков обладает определенными психологическими, возрастными, технологическими навыками и характеристиками, различен и уровень родитель- ского контроля, и опыт взаимодействия с медиа. Поэтому мотивационные факторы телевизионного потребления даже в рамках девятилетней разницы (10-19 лет) будут существенно отличаться.

\section{Примечания}

${ }^{1}$ Исследование выполнено за счет средств гранта Российского научного фонда (проект № 18-78-10090).

2 Федеральная служба государственной статистики // Демография. Численность и состав населения. Распределение населения по возрастным группам. Режим доступа: https://www.gks.ru/folder/12781 (дата обращения: 06.02.2020).

3 Телевидение в России в 2018 году. Состояние, тенденции и перспективы развития. Отраслевой доклад. М.: ФАПМК, 2019. С. 38. Режим доступа: http://www. fapmc.ru/rospechat/activities/reports/2019/teleradio/main/custom/0/01/file.pdf (дата обращения: 06.02.2020).

${ }^{4}$ Детское медиапотребление. Что интересно юной аудитории в Интернете и на ТВ // Adindex.ru. 2019. Март, 18. Режим доступа: https://adindex.ru/news/ researches/2019/03/17/270654.phtml (дата обращения: 06.02.2020).

\section{Библиография}

Аникина М.Е. Медиапотребление российских школьников: центр и регионы // МедиаАльманах. 2017. № 4. С. 50-62.

Вартанова Е.Л. Цифровое телевидение и трансформация медиасистем. О необходимости междисциплинарных подходов к изучению современного ТВ // Вестн. Моск. ун-та. Сер. 10: Журналистика. 2011. № 4. С. 6-26.

Кульчицкая Д.Ю., Вартанов С.А., Дунас Д.В., Салихова Е.А. и др. (а) Медиапотребление молодежи: специфика методологии исследования // Медиаскоп. 2019. Вып. 1. Режим доступа: http://www.mediascope.ru/2529 DOI: 10.30547/mediascope.1.2019.9

Кульчицкая Д.Ю., Вартанов С.А., Дунас Д.В., Салихова Е.А. и др. (б) Теоретические аспекты изучения медиапотребления российской молодежи: к пересмотру теории использования и удовлетворения // Вестн. Моск. ун-та. Сер. 10: Журналистика. 2019. № 2. C. 3-28. DOI: 10.30547/vestnik.journ.2.2019.328

Лащук О.Р., Толоконникова А.В., Хорошилова Ж.Н. Детское телевизионное вещание: мониторинг сегмента в аспекте лингвистического анализа // МедиаАльманах. 2018. № 4. C. 14-22. DOI: 10.30547/mediaalmanah.4.2018.1422

Образцова А.Ю. Особенности медиапотребления детей школьного возраста (на примере г. Углича) // Медиаскоп. 2014. Вып. 4. Режим доступа: http://www.mediascope.ru/1648

Образцова А.Ю., Фролова Т.И. Медиаграмотность школьников в оценке учителей и родителей: результаты исследования // Вестн. Моск. ун-та. Сер. 10: Журналистика. 2017. № 4. С. 58-77.

Полуэхтова И.А. Динамика мотивационной структуры телепотребления россиян // Медиаскоп. 2018. Вып. 4. Режим доступа: http://www.mediascope.ru/2508. DOI: 10.30547/mediascope.4.2018.8 
Полуэхтова И.А. Исследования аудитории и медиапотребления в цифровой среде: методологические и практические проблемы // Медиаскоп. 2016. Вып. 4. Режим доступа: http://www.mediascope.ru/2199

Эльконин Д.Б. Избранные психологические труды. М.: Педагогика, 1989.

Bhatti M. A., Hassan A.A.U. (2014) Psychological Effects of TV News Violence on Youth: A Case Study of the Students of Bahauddin Zakariya University, Multan. Pakistan Journal of Social Sciences (PJSS) 34 (1): 295-305.

Blumler J.G., Katz E. (1974) The Uses of Mass Communications: Current Perspectives on Gratifications Research. Beverly Hills, CA: Sage.

Greenberg B. (1974) Gratification of Television Viewing and Their Correlates for British Children. In: Blumler H., Katz E. (eds.). The Uses of Mass Communications. Beverly Hills: Sage, pp. 71-92.

Howe N., Strauss W. (2007) Millenials \& K-12 Schools: Educational Strategies for a New Generation. Great Falls: LifeCourse Associates.

Khurana A., Bleakely A., Ellithrope M.E., Hennessy M. et al. (2019) Media Violence Exposure and Aggression in Adolescents: A Risk and Resilience Perspective. Aggressive Behavior 45 (1): 70-81. DOI: https://doi.org/10.1002/ab.21798

McQuail D., Blumler J.G, Brown J. (1972) The Television Audience: A Revised Perspective. In: McQuail D. (ed.) Sociology of Mass Communication. Harmondsworth: Penguin, pp. 135-165.

Mares M.L., Sivakumar G., Stephenson L. (2015). From Meta to Micro: Examining the Effectiveness of Educational TV. American Behavioral Scientist 59 (14): 1822-1846. DOI: https://doi.org/10.1177/0002764215596555

Masur E.F., Flynn V., Olson J. (2015). The Presence of Background Television During Young Children's Play in American Homes. Journal of Children and Media 9 (3): 349-367. DOI: https://doi.org/10.1080/17482798.2015.1056818

Pempek T.A., Kirkorian H.L., Anderson D.R. (2014) The Effects of Background Television on the Quantity and Quality of Child-Directed Speech by Parents. Journal of Children and Media 8 (3): 211-222. DOI: 10.1080/17482798.2014.920715

Scherr S., Mares M.-L., Bartsch A., Götz M. (2017) On the Relevance of Parents and TV as Socializers of 6-19 Year-olds' Expressions of Emotion: Representative Data from Germany. Journal of Children and Media 12 (1): 33-50. DOI: 10.1080/17482798.2017.

Shim H., Kim K.J. (2018) An Exploration of the Motivations for Binge-Watching and the Role of Individual Differences. Computers in Human Behavior 82: 94-100. DOI: 10.1016/j.chb.2017.12.032

Zillmann D., Bryant J. (1985) Affect, Mood, and Emotion as Determinants of Selective Exposure. In: Zillmann D., Bryant J. (eds.) Selective Exposure to Communication. Hillsdale: Lawrence Erlbaum Associates, pp. 113-139. 